\title{
Ambient noise tomography in the Naruko/ Onikobe volcanic area, NE Japan: implications for geofluids and seismic activity
}

\author{
Jun Tamura ${ }^{1,2^{*}}$ and Tomomi Okada ${ }^{1}$
}

\begin{abstract}
To understand the earthquake generation in volcanic areas, it is important to investigate the presence of geofluids in the uppermost crust. We applied ambient noise tomography to the Naruko/Onikobe volcanic area and constructed a detailed 3-D S-wave velocity $\left(V_{s}\right)$ model using continuous records from a dense seismic network and surrounding stations. The low-velocity zones were found beneath Naruko Volcano, Onikobe Caldera, and Mt. Kurikoma. The low-velocity zone beneath Onikobe Caldera may correspond to a magma reservoir, which is also characterized by surrounding S-wave reflectors. The molten magma originates from the upwelling flows in the mantle wedge. We also conducted the relocation of aftershocks of the 2008 Iwate-Miyagi Nairiku earthquake by double-difference tomography based on the obtained velocity model. Beneath Mt. Kurikoma, aftershock distribution delineates one of the unfavorably oriented fault planes of the main shock, which implies that the low-velocity zone around the fault plane is related to the presence of overpressurized fluid.
\end{abstract}

Keywords: Geofluids, Ambient noise tomography, 2008 Iwate-Miyagi Nairiku earthquake, Naruko Volcano

\section{Introduction}

The Naruko/Onikobe volcanic area is located on the volcanic front of the NE Japan arc (Fig. 1), where the Pacific Plate is subducting along the Japan Trench beneath the North American Plate. Along with the subduction, hydrated minerals in the oceanic plate (Pacific Plate) are dehydrated under high temperature and pressure, and water is released from the underlying plate to the mantle wedge. This water migrates as upwelling flows in the mantle wedge and eventually reaches the crust beneath the volcanic front. The study area is one of the typical geo- and hydro-thermally active areas generated under this system, and the area includes two active Quaternary volcanoes (Naruko Volcano and Mt. Kurikoma). The latest eruption of Naruko Volcano occurred in 837, and

\footnotetext{
* Correspondence: jtamura9@gmail.com

${ }^{1}$ Research Center for Prediction of Earthquakes and Volcanic Eruptions, Graduate School of Science, Tohoku University, Sendai, Miyagi 980-8578, Japan

${ }^{2}$ Present address: JX Nippon Oil \& Gas Exploration Corporation, 6-3, Otemachi 2-chome, Chiyoda-ku, Tokyo 100-8163, Japan
}

Mt. Kurikoma underwent small eruptions in 1744, 1783, and 1944. In addition to these active volcanoes, there are two calderas (Onikobe and Mukaimachi Calderas), which were formed approximately $50 \mathrm{ka}$ ago and during the Pliocene, respectively.

This region is influenced by the Tohoku backbone range strain concentration zone along the volcanic front (Miura et al. 2004), and compressional inversion tectonics are predominant (Sibson 2009). This is explained by the relative motion of the plate subduction in the EW direction and the crustal softening due to geofluids such as molten magma and geothermal water in the crust (Hasegawa et al. 2009). Many normal faults were formed under the extensional stress regime during the Miocene when the Japan Sea opened, and they act as reverse faults under the current compressional stress regime (Okada et al. 2012). Consequently, several large shallow earthquakes with reverse-type focal mechanisms have occurred in and around the study area [e.g., the 2003 northern Miyagi earthquake $(M$ 6.4) and the 2008 Iwate-Miyagi Nairiku earthquake (M 7.2)].

\section{Springer}




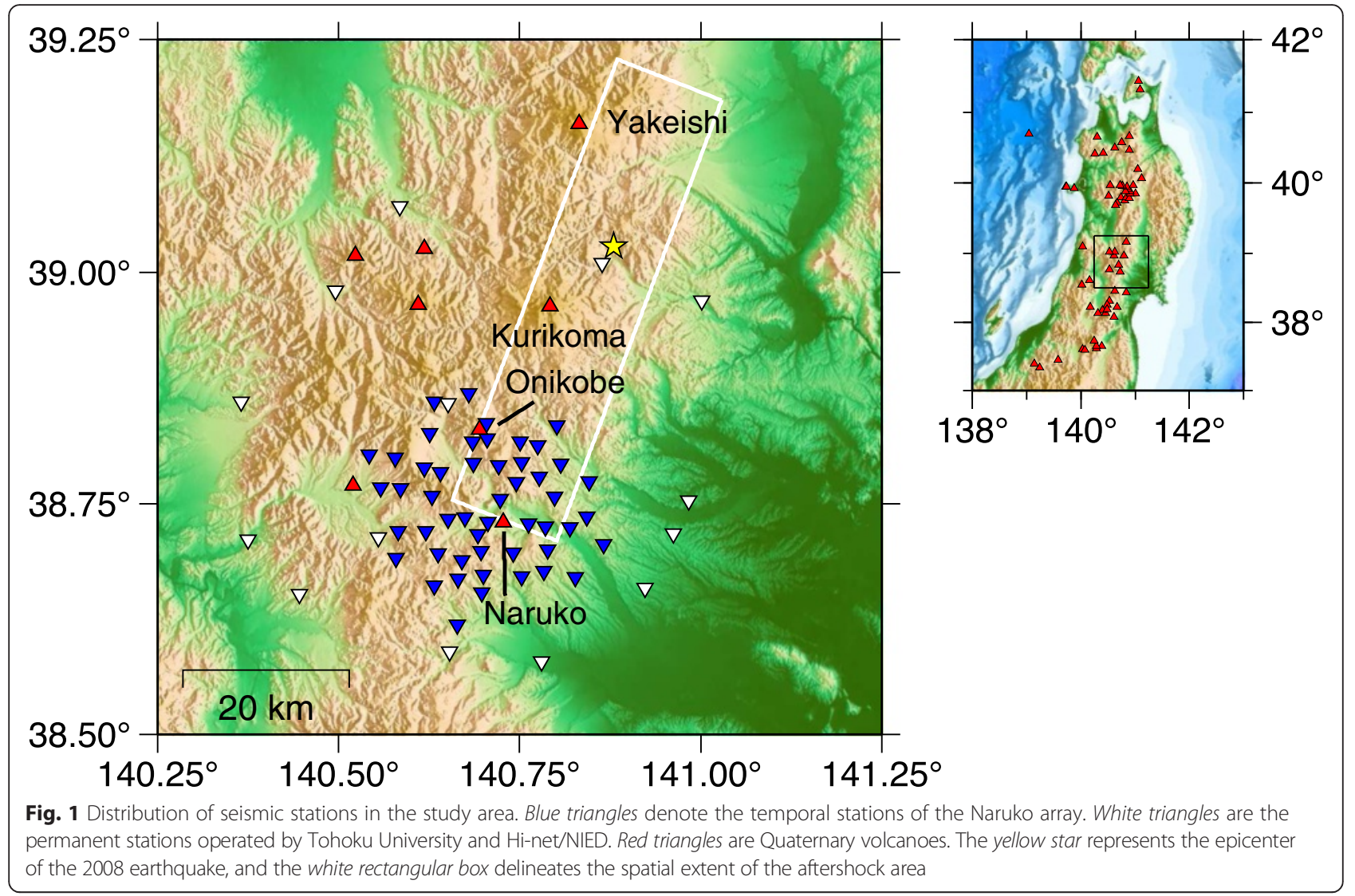

The 2008 Iwate-Miyagi Nairiku earthquake occurred in the central part of NE Japan on June 14, 2008. The earthquake was typical of inland (intraplate) earthquakes in NE Japan, and its magnitude was 7.2. The focal mechanism was reverse-type with a NW-SE-oriented $P$-axis. A large slip occurred along the westward dipping plane (e.g., Ohta et al. 2008), although conjugate faulting also occurred along the eastward dipping plane (e.g., Takada et al. 2009). The spatial extent of the aftershock area was approximately $60 \mathrm{~km}$ in the strike direction. The aftershock area extended further south of the large slipped area (e.g., Iinuma et al. 2009), and the study area corresponds to the southwest end of the aftershock area. Before the 2008 earthquake, preceding seismic events occurred on the same fault plane in the vicinity of the mainshock of the 2008 earthquake, including an $M 4.5$ earthquake on April 19, 1999, and an M 4.9 earthquake on February 11, 2000 (Okada et al., 2012).

Several seismic tomography studies have been carried out in and around the focal area, and distinct low-velocity zones (LVZ) with high $\mathrm{P}$-wave velocity $\left(V_{\mathrm{p}}\right) / V_{\mathrm{s}}$ have been recognized in the lower crust beneath volcanoes (Nakajima and Hasegawa 2003; Okada et al. 2010; Okada et al. 2012; Okada et al. 2014). They are considered to be molten magma originating from the upwelling flows in the mantle wedge. In addition, some LVZs with high $V_{\mathrm{p}} / V_{\mathrm{s}}$ in the upper crust are thought to be overpressurized fluid (Okada et al. 2012). At present, however, the structures of the volcanoes and calderas remain unclear because seismic body-wave tomography cannot resolve structures in the uppermost crust. Detailed information on volcanic structures is therefore necessary to understand the relationship between probable geofluids and the generation of earthquakes.

With the development of seismic interferometry, which provides the Green's function of wave propagation between a pair of stations from the correlation of ambient noise recordings, its application to tomography has developed greatly in recent years. The tomography technique is referred to as ambient noise tomography (ANT) and has been applied at various scales depending on the frequency ranges of microseisms and sensors. The microseismic band containing ambient noise ranges approximately from 0.05 to $1.0 \mathrm{~Hz}$, at which the primary and secondary microseisms are generated at the sea floor with different mechanisms (Longuest-Higgins 1950; Hasselmann 1963). Because surface waves at these frequencies are sensitive to a few tens of kilometers in depth, ANT has been applied to many regions to study crustal structures (e.g., Shapiro et al. 2005; Moschetti et al. 2007; Lin et al. 2008; Li et al. 2009; Yang et al. 2011; Nicolson et al. 2012). At local scales, ANT has proven to be an effective tool for imaging 
volcanic structures (e.g., Masterlark et al. 2010; Jay et al. 2012; Nagaoka et al. 2012; Jaxybulatov et al. 2014; Mordret et al. 2015; Shomali and Shirzad 2015).

In this study, we perform ANT using continuous noise records observed by a dense seismic network and surrounding seismic stations. We present the results and discuss the presence of geofluids and their relationship to the aftershock distribution of the 2008 earthquake.

\section{Data and methods}

We used continuous velocity records from October 2010 to March 2012 observed by 14 permanent stations and 50 dense temporary stations (Okada et al. 2014). Figure 1 shows the station distribution in the study area. The permanent stations include $1-\mathrm{Hz}$ short-period sensors operated by Hi-net/NIED and Tohoku University. The temporary stations, which we call the Naruko array, comprise short-period sensors with a natural frequency of $2 \mathrm{~Hz}$ and are operated by Tohoku University. The average interval of the Naruko array is a few kilometers. The sampling frequency of all the sensors used in this study is $100 \mathrm{~Hz}$. We only used the vertical components of seismographs to extract Rayleigh waves, which have predominant sensitivity to $\mathrm{SV}$-wave velocity. In our processing, ambient noise tomography was performed as follows: (1) preprocessing, (2) noise cross-correlation, (3) dispersion curve measurement, (4) tomographic inversion, and (5) construction of a 3-D $V_{\mathrm{s}}$ model.

During the preprocessing (1) and noise correlation (2) stages, we generally followed the method of Bensen et al. (2007). Data were divided into 10-min segments with an overlap of $5 \mathrm{~min}$ and down-sampled from 100 to $20 \mathrm{~Hz}$, and instrumental correction was then applied. Next, mean removal and spectral whitening were performed for each segment to constrain earthquake signals. Crossspectra were then calculated for each pair of segments and stacked over a period available for each pair of stations. The stacking periods ranged from 4 to 18 months because of the maintenance and deployment of stations. Figure 2 shows paste-ups of cross-correlation functions filtered in bands of $0.1-0.2 \mathrm{~Hz}$ and $0.2-0.4 \mathrm{~Hz}$. Wave trains appear at both negative and positive lag times with a propagation velocity of approximately $3 \mathrm{~km} / \mathrm{s}$. We assume that Rayleigh waves, generated by the nonlinear interaction of the ocean waves (Longuest-Higgins 1950), are fairly dominant in this frequency range.

In the third stage, we performed the dispersion curve measurement. Conventionally, frequency-time analysis (FTAN) (e.g., Dziewonski et al. 1969; Bensen et al. 2007) has been used in most ambient noise studies to extract group velocity dispersion curves from empirical Green's functions (EGF). Here, a narrow-band filter is applied to an EGF, and the group velocity at the central frequency of the filter is then measured from the envelope peak of the filtered EGF. The group velocity can also be converted into phase velocity, if intrinsic and source phase uncertainties are determined (e.g., Lin et al. 2008). One of the restrictions in this method is that a short interstation distance should be avoided for the far-field approximation in the interpretation of the time-domain signal. Generally, the method is restricted to greater than one wavelength for local scales (e.g., Masterlark et al. 2010) and three wavelengths for regional scales (e.g., Lin et al. 2008; Yang et al. 2011). However, some studies have conducted the measurement of phase velocity dispersion curves by employing the spatial autocorrelation (SPAC) method (Aki 1957), which is theoretically free from interstation distance. Ekström et al. (2009) retrieved dispersion curves by correlating the zero-crossing positions of cross-spectra with those of the Bessel function. The spatial patterns of their tomography results are quite similar to those from the FTAN method. Nagaoka et al. (2012) performed the measurement in two steps; they first determined a reference dispersion curve and then
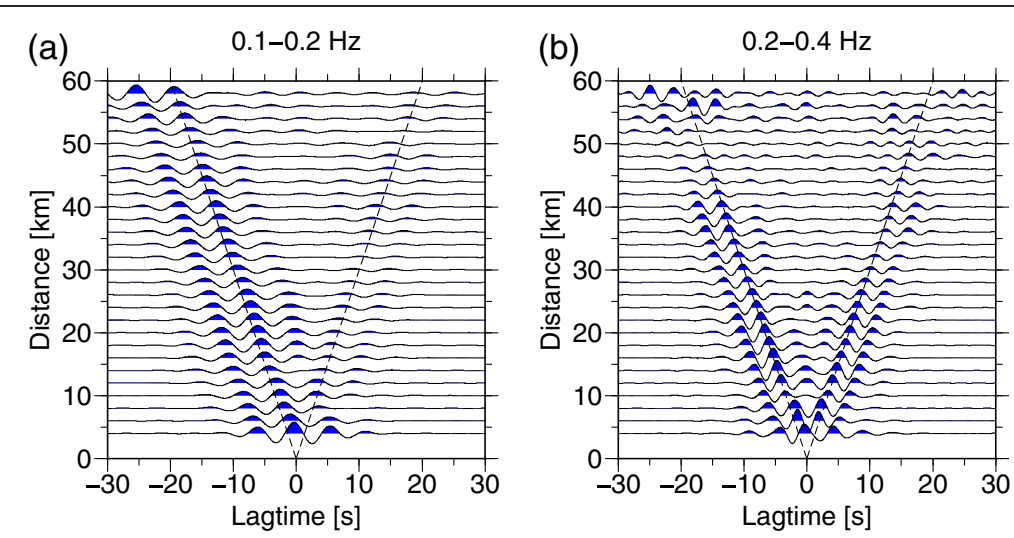

Fig. 2 Paste-ups of cross-correlation functions in the frequency bands of $\mathbf{a} 0.1-0.2 \mathrm{~Hz}$ and $\mathbf{b}$ 0.2-0.4 Hz. Cross-correlation functions are aligned depending on their back azimuth and interstation distance. Each waveform is averaged over every $2 \mathrm{~km}$ of interstation distance. Broken lines indicate the travel time of waves with a propagation velocity of $3 \mathrm{~km} / \mathrm{s}$ 
perturbed it for individual ray paths. These SPAC-based methods use the real part of the stacked cross-spectra, which is equivalent to the even part of the crosscorrelation functions used in the FTAN method. In this study, we adopted the two-step technique of Nagaoka et al. (2012) because it is robust against the anisotropic distribution of ambient noise. In the first step, we estimated a reference dispersion curve by fitting the zero-order Bessel function of the first kind to the observed cross-spectra of all station pairs at each frequency, thereby obtaining reference cross-spectra. Figure 3a shows the results of the grid search for the determination of the reference dispersion curve. The figure shows a clear fundamental Rayleigh wave branch up to $0.45 \mathrm{~Hz}$. This curve is similar to the dispersion curve produced from the JMA2001 model (Ueno et al. 2002). In the second step, we measured the phase velocity for each station pair by searching a phase shift between the observed and the reference cross-spectra within a frequency band of interest. A phase shift can be represented by a perturbation from the reference velocity, and thus, we derived the measured phase velocity for each frequency band. The frequency bands were set as follows: a central frequency range from 0.15 to $0.40 \mathrm{~Hz}$ with a bandwidth of $0.05 \mathrm{~Hz}$, and a frequency step of $0.025 \mathrm{~Hz}$. To select reliable measurements, we set up four criteria: interstation distance, phase detection, quality control, and outlier removal. First, interstation distance must be greater than the second zerocrossing of the reference spectra in the direction of the increasing frequency. This is because it is difficult to find a phase shift at small distances because of the small number of zero-crossings in the cross-spectra. Furthermore, Green's functions extracted at small interstation distance are more susceptible to anisotropic noise distribution (e.g., Weaver et al. 2009; Froment et al. 2010). The second criterion applies to the phase detection stage. The initial perturbation was searched for within $20 \%$ of the reference, and the subsequent perturbation was restricted to a range within $7 \%$ of the previous frequency band, which is similar to Nagaoka et al. (2012). When no minimum fitting was found within the search range, we stopped measuring the phase velocity in the following bands. Third, the variance reduction obtained from the phase detection must be greater than 0.3 as a quality control. Finally, we discarded phase velocities that fell outside the 3-sigma range at each central frequency as to remove outliers. Table 1 summarizes the number of ray paths that fulfilled the four criteria. Figure 3b shows two examples of measured phase velocity dispersion curves on two straight ray paths. The path between IKS02 and NRK07 (green line) passes through Onikobe Caldera and on the western side of Naruko Volcano. The path between MKM01 and N.OGCH (blue line) passes on the outer rims of the calderas. The phase velocity on the path between IKS02 and NRK07 is lower than that on the path between MKM01 and N.OGCH. In particular, there is a significant velocity reduction between 0.15 and $0.30 \mathrm{~Hz}$, which implies the presence of a soft material at depths of approximately 4 to $6 \mathrm{~km}$.

In stage 4 , we inverted the phase velocity measurements for the $2-\mathrm{D}$ phase velocity maps on a $0.04^{\circ} \times 0.04^{\circ}$ grid at central frequencies from 0.15 to $0.40 \mathrm{~Hz}$. The tomography was performed using the linear inversion technique of Barmin et al. (2001), which assumes the
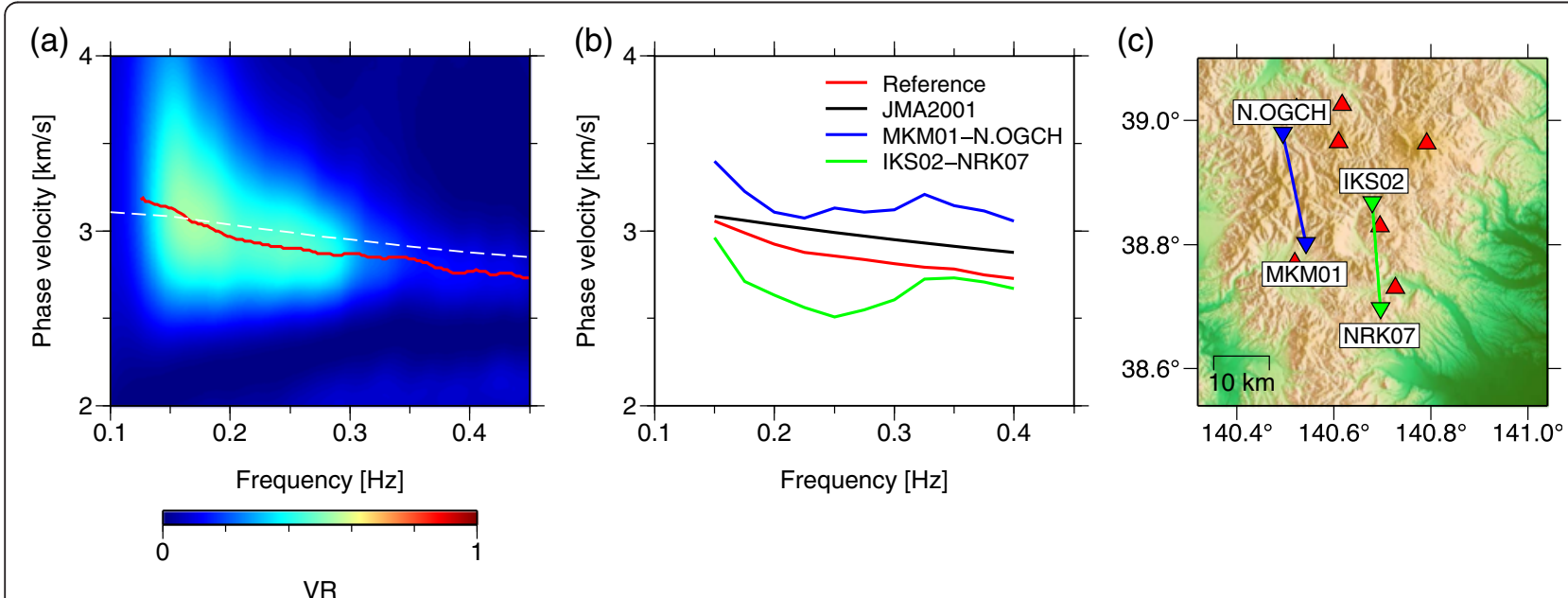

Fig. 3 Reference and measured phase velocity dispersion curves. a Variance reductions for the determination of the reference dispersion curve. The red line is the reference curve determined by grid search, and the white dashed line represents a dispersion curve produced from the JMA2001 model. b Dispersion curves from the ray paths shown in c. The red and black lines represent the reference dispersion curve and the dispersion curve produced from the JMA model, respectively. c Ray paths of station pairs MKM01-N.OGCH (blue) and IKS01-NRK07 (green). Red triangles are Quaternary volcanoes 
Table 1 Numbers of ray paths selected by the data selection criteria at each frequency

\begin{tabular}{ll}
\hline Frequency $[\mathrm{Hz}]$ & Number of paths \\
\hline 0.150 & 588 \\
0.175 & 746 \\
0.200 & 850 \\
0.225 & 864 \\
0.250 & 845 \\
0.275 & 819 \\
0.300 & 744 \\
0.325 & 703 \\
0.350 & 651 \\
0.375 & 598 \\
0.400 & 565 \\
\hline
\end{tabular}

great-circle path propagation. A damping parameter was introduced to regularize the objective function, and the optimal value was determined by the trade-off curve between model variance and the RMS residual. For the a priori covariance matrix, we assumed a diagonal matrix whose elements are the observational error of $0.13 \mathrm{~km} / \mathrm{s}$ based on phase velocity measurements on the similar ray paths. Figure 4 shows the phase velocity maps at 0.2 and $0.4 \mathrm{~Hz}$. At $0.2 \mathrm{~Hz}$, a distinct LVZ with a diameter of about $10 \mathrm{~km}$ is seen beneath Onikobe Caldera and a small LVZ with a diameter of about $5 \mathrm{~km}$ is seen southwest of Naruko Volcano. At $0.4 \mathrm{~Hz}$, these LVZs become smaller; the radii of LVZs beneath Onikobe Caldera and Naruko Volcano are approximately $5 \mathrm{~km}$. Other LVZs are found beneath several volcanoes including Mt. Kurikoma, although those outside the Naruko array were imaged as artifacts due to poor path coverage. To check the recoverability with the given path coverage, we conducted checkerboard resolution tests. Input models were produced by alternatingly placing cells with a $\pm 20 \%$ perturbation from the background velocity. Figure $5 \mathrm{a}$ shows the input and output models with $0.04^{\circ}$ by $0.04^{\circ}$ anomalies for the path coverage at $0.2 \mathrm{~Hz}$, and Fig. $5 \mathrm{~b}$ shows those with $0.08^{\circ}$ by $0.08^{\circ}$ anomalies. Anomalies in the area enclosed by the Naruko array are fairly well resolved for both tests. However, the poor path coverage outside the Naruko array yields linear artifacts. It should also be noted that the assumption of the great-circle path propagation may not account for the focusing and defocusing effects of anomalies as large as $20 \%$, and the geometrical ray approximation may overestimate their size (Yoshizawa and Kennett 2002).

In stage 5, we inverted the obtained phase velocities for a 1-D $V_{\mathrm{s}}$ profile at every grid point, thereby constructing a 3-D $V_{\mathrm{s}}$ model. We used the linearized inversion algorithm

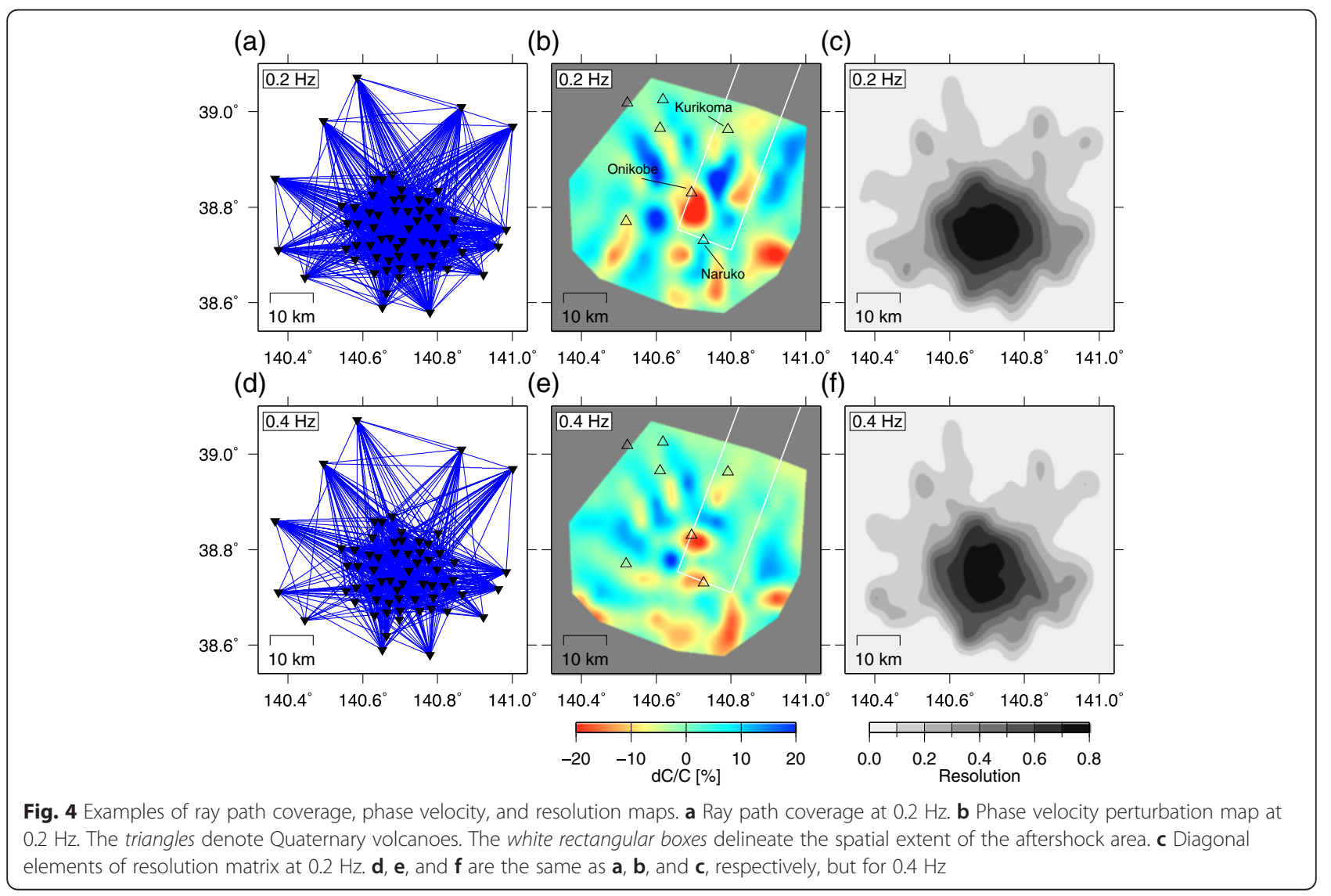




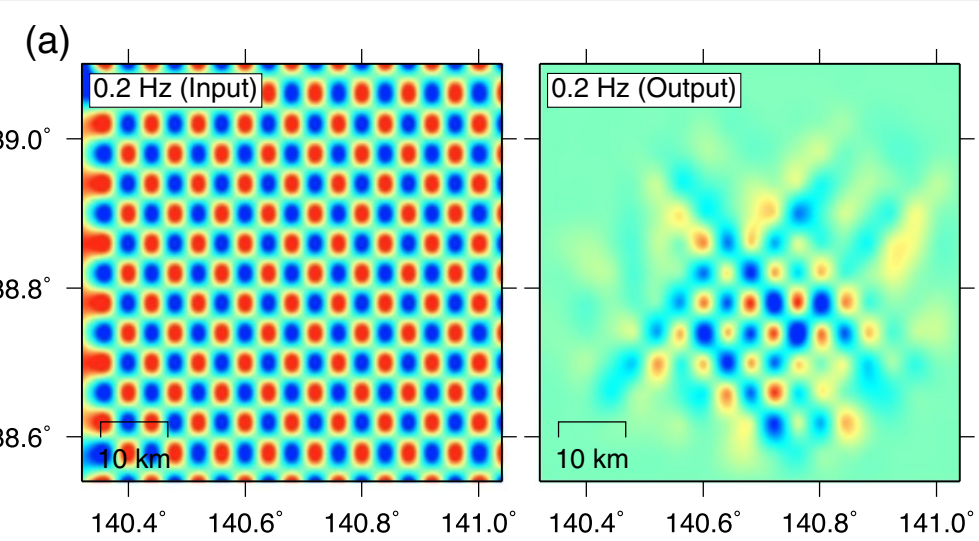

(b)

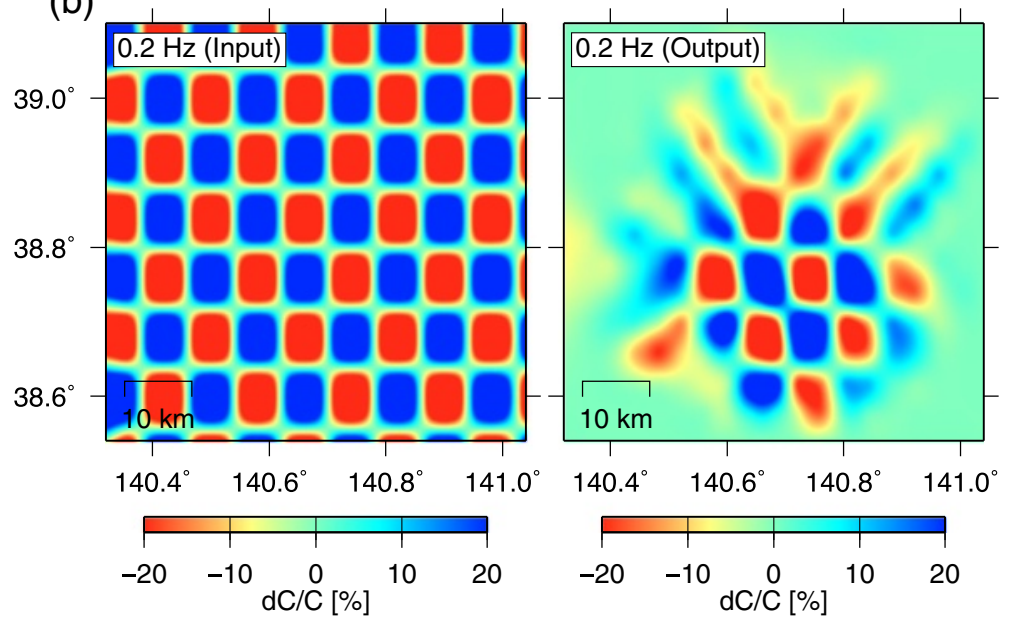

Fig. 5 Checkerboard tests. a Input (left) and output (right) models with $0.04^{\circ}$ by $0.04^{\circ}$ anomalies at $0.2 \mathrm{~Hz}$. $\mathbf{b}$ The same as a but with $0.08^{\circ}$ by $0.08^{\circ}$ anomalies

described in Tarantola and Valette (1982). The objective function to be minimized is

$$
\mathbf{m}_{i+1}=\mathbf{m}_{0}+\mathbf{C}_{m} \mathbf{G}_{i}^{T}\left(\mathbf{C}_{d}+\mathbf{G}_{i} \mathbf{C}_{m} \mathbf{G}_{i}^{T}\right)^{-1}\left(\mathbf{d}-\mathbf{g}\left(\mathbf{m}_{i}\right)+\mathbf{G}_{i}\left(\mathbf{m}_{i}-\mathbf{m}_{0}\right)\right)
$$

where $\mathbf{d}$ is the data vector and $\mathbf{m}_{0}$ and $\mathbf{m}_{i}$ are the reference and $i$ th model vectors, respectively. $\mathbf{g}$ is the functional of the model vectors, and $\mathbf{G}_{i}$ is the kernel matrix for the $i$ th model, which is calculated by the DISPER 80 program (Saito 1988). The a priori covariance matrix of data vectors $\mathbf{C}_{d}$ is assumed to be diagonal and composed of the square of uncertainties. Following Nataf et al. (1986), we took into account the smooth variation of the parameters and the geophysical relationship among parameters by employing the a priori covariance matrix of model vectors $\mathbf{C}_{m}$ defined as

$$
\mathbf{C}_{m}(i, j)=\sigma^{2} \exp \left(-\left(r_{i}-r_{j}\right)^{2} / 2 \Delta^{2}\right)
$$

where $\sigma$ is the a priori standard deviation treated as a hyper parameter, $r_{i}$ is the depth of the $i$ th layer, and $\Delta$ is the vertical correlation distance that acts as a smoothing factor. The vertical correlation distance was set to $1 \mathrm{~km}$, without significant vertical smearing. A priori standard deviations were selected from the range between 0.1 and $1.0 \mathrm{~km} / \mathrm{s}$, and an optimal value was determined from the trade-off curve between model variance and the RMS residual. During the inversion, a model was substantially parameterized by $\mathrm{S}$-wave velocity in eight layers from the surface down to a depth of $8 \mathrm{~km}$ with a thickness of $1 \mathrm{~km}$. For simplicity, the P-wave velocity was scaled as a function of S-wave velocity based on the empirical relation described in Brocher (2005), and the density was subsequently scaled by the inferred P-wave velocity using Gardner's rule (Gardner et al. 1974). Uncertainties of data were uniformly taken to be $0.1 \mathrm{~km} / \mathrm{s}$ based on the a posteriori error covariance matrix of the surface tomography, as it is difficult to obtain exact estimates. Although this is arbitrary for the absolute values of uncertainties in the S-wave velocity, the relative values with depth will be preserved. We took the JMA2001 model (Ueno et al., 2002) as an initial model and iterated the inversion 20 times to obtain an optimal model. Examples 
of $V_{\mathrm{s}}$ profiles and phase velocity dispersion curves at two grid points inside Onikobe Caldera and on its outer rim are shown in Fig. 6. As can be seen in the figure, the $V_{\mathrm{s}}$ profile inside the caldera shows a significant low velocity compared with that on the outer rim.

\section{Results and discussion}

Figure 7 shows the $V_{\mathrm{s}}$ model in map view at depths of 1 , 3 , 5 , and $7 \mathrm{~km}$ plotted as perturbations from the JMA2001 model. At 1- and 3-km depths, two small LVZs are found beneath Naruko Volcano and Onikobe Caldera. At greater depths, the LVZs beneath Naruko Volcano and Onikobe Caldera shift southwestward and southward, respectively. While the distinct LVZ beneath Onikobe Caldera has been recognized in previous studies (e.g., Nakajima and Hasegawa 2003; Okada et al. 2014), the LVZ beneath Naruko Volcano had previously been resolved only by a magnetotelluric survey (Ogawa et al. 2014). We also found a LVZ beneath Mt. Kurikoma although it does not lie in the area with a resolution matrix entry greater than 0.3 at $0.4 \mathrm{~Hz}$. This LVZ extends approximately $15 \mathrm{~km}$ southward at depths of 5 and $7 \mathrm{~km}$. The LVZs in the south and southeast correspond to a sedimentary basin as mentioned in Okada et al. (2014). To discuss the LVZs mentioned above, we compared our results with the distribution of aftershocks of the 2008 earthquake and S-wave reflectors.

To investigate the relationship between the LVZs in our model and the aftershock distribution of the 2008 earthquake, we performed hypocenter relocation using the double-difference tomography method (Zhang and Thurber, 2003). We used P- and S-wave arrival time data recorded at stations shown in Fig. 8 (blue squares) in the period from June 14 to September 30, 2008, which is the same dataset as Okada et al. (2012). The number of stations and aftershocks are approximately 300 and 26,000, respectively. We used the $V_{\mathrm{s}}$ model obtained in this study and a $V_{\mathrm{p}}$ model scaled from the $V_{\mathrm{s}}$ model by the relation in Brocher (2005) for an input velocity model. The minimum magnitude was set as 1.5, and 2849 hypocenters were consequently relocated from the JMA unified catalog. The accuracy of the aftershock relocation was less than $100 \mathrm{~m}$. Aftershocks were distributed avoiding the LVZ beneath Onikobe Caldera, which can be explained by material softening under very high temperature of molten magma. Takada and Fukushima (2013) revealed volcanic subsidence triggered by the 2011 Tohoku earthquake (M 9.0) by InSAR analysis. The location of the detected subsidence beneath Onikobe Caldera is in excellent agreement with that of the LVZ, which supports the presence of magmatic and hot plutonic bodies underneath.

Hori et al. (2004) discovered many reflected S-waves $\mathrm{SxS}$ at velocity boundaries within the crust in seismograms of local earthquakes. They estimated locations of those boundaries based on arrival time differences between the SxS and direct S-waves with an accuracy of less than $100 \mathrm{~m}$. These reflectors can be interpreted as thin fluid-filled cracks (Matsumoto and Hasegawa 1996; Umino et al. 2002) that would be produced under high pressure and filled with geofluids.

Figure 9a shows the obtained $V_{\mathrm{s}}$ model in a crosssectional view. Along lines $\mathrm{A}-\mathrm{A}^{\prime}$ and $\mathrm{C}-\mathrm{C}$, we see that many reflectors are distributed encircling the outline of the LVZ beneath Onikobe Caldera at depths between 2 and $7 \mathrm{~km}$, and no reflector is found inside. This implies that cracks are not produced inside the LVZ due to very high

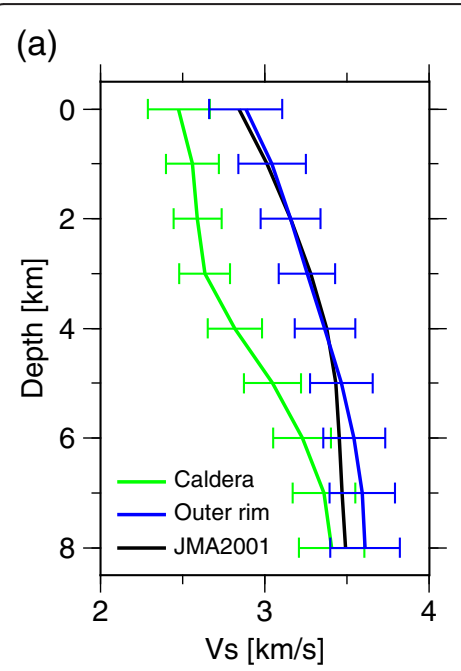

(b)

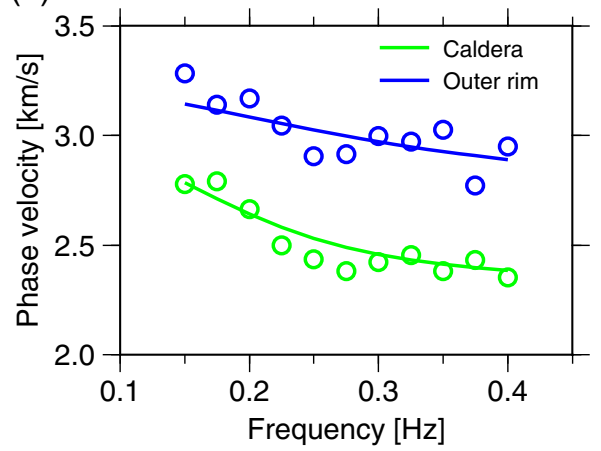

(c)

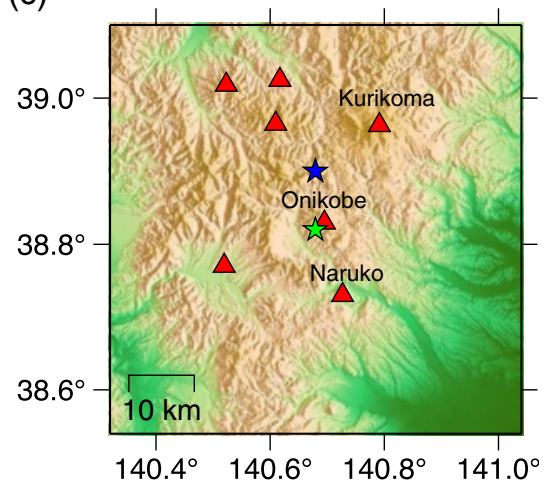

Fig. 6 Examples of $V_{s}$ inversion results. a $V_{s}$ models produced by linearized inversion at two grid points shown in c Error bars are calculated from a posteriori covariance matrix of model parameters. The black curve is the initial model. $\mathbf{b}$ Phase velocity dispersion curves from the phase velocity maps (small circles). Solid lines are the dispersion curves modeled by the inversion. c Locations of the two grid points inside Onikobe Caldera (green star) and on its outer rim (blue star) 


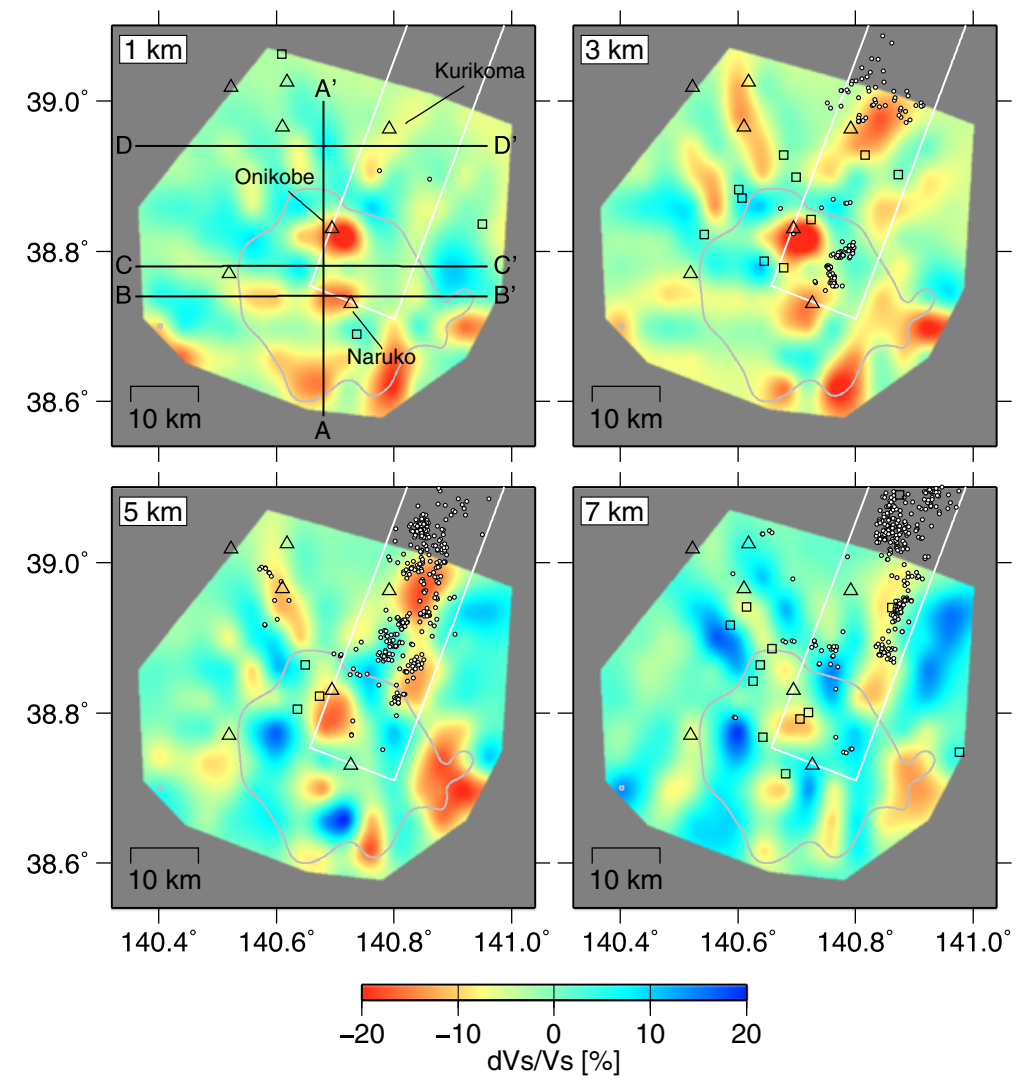

Fig. $7 \mathrm{~V}_{\mathrm{s}}$ model in map view at the depths of 1,3,5, and $7 \mathrm{~km}$. The perturbations from the JMA2001 model are plotted. Triangles and squares represent the locations of Quaternary volcanoes and S-wave reflectors, respectively. White circles denote aftershocks with a depth range of $\pm 0.25 \mathrm{~km}$. A gray contour indicates 0.3 of the diagonal elements of the resolution matrix at $0.4 \mathrm{~Hz}$. Lines A-A', B-B', C-C', and D-D' represent the locations of cross sections for Fig. 8

temperature of the molten magma, but they would be produced around it filled with geothermal water or molten magma. The LVZ beneath Naruko (lines A-A' and B-B') and the shallower part of the LVZ beneath Onikobe Caldera (line A-A') imply weak materials such as volcanic deposits, fluid-saturated materials, or partial molten magma. Beneath Mt. Kurikoma (line D-D'), aftershocks around the LVZ appeared to be distributed along a fault, which corresponds to one of the unfavorably oriented faults mentioned in Okada et al. (2012). The relocated aftershock distribution in their study delineate the complex fault planes dipping westward and eastward and imply the presence of overpressurized fluid as a plausible cause of the reactivation of the misoriented faults (Sibson 1990). Based on an analysis of the diversity of focal mechanisms, Yoshida et al. (2014) also concluded that areas of higher pore pressure are distributed around the large coseismic slip area near Mt. Kurikoma.

Figure $9 \mathrm{~b}$ shows the $V_{\mathrm{s}}$ model and the aftershock distribution of Okada et al. (2012) determined by doubledifference tomography. In comparison with this model, the model in this study is able to resolve smaller velocity anomalies. As a result, the distribution of aftershock relocation is improved; some aftershocks at very shallow depths shift reasonably deeper (line $\mathrm{C}-\mathrm{C}^{\prime}$ ), and others are more closely aligned on the fault trend (line D-D').

\section{Conclusions}

A 3-D $V_{\mathrm{s}}$ model determined by ANT revealed detailed velocity structures beneath volcanoes in the Naruko/ Onikobe volcanic area. The LVZs in the uppermost crust are better resolved than in previous seismic tomography studies. Combined with the distribution of S-wave reflectors and aftershocks of the 2008 earthquake, the LVZs are characterized as molten magma or overpressurized fluid. The aseismic LVZ surrounded by S-wave reflectors beneath Onikobe Caldera may correspond to a magma reservoir. The molten magma, which is recognized in the lower crust as high $V_{\mathrm{p}} / V_{\mathrm{s}}$ LVZs by previous seismic tomography studies, originates from upwelling flows in the mantle wedge. Around the LVZ beneath Mt. Kurikoma, aftershock distribution delineates a fault plane, which corresponds to one of the misoriented fault planes of the mainshock of the 2008 earthquake. As suggested in previous studies, the presence of overpressurized 


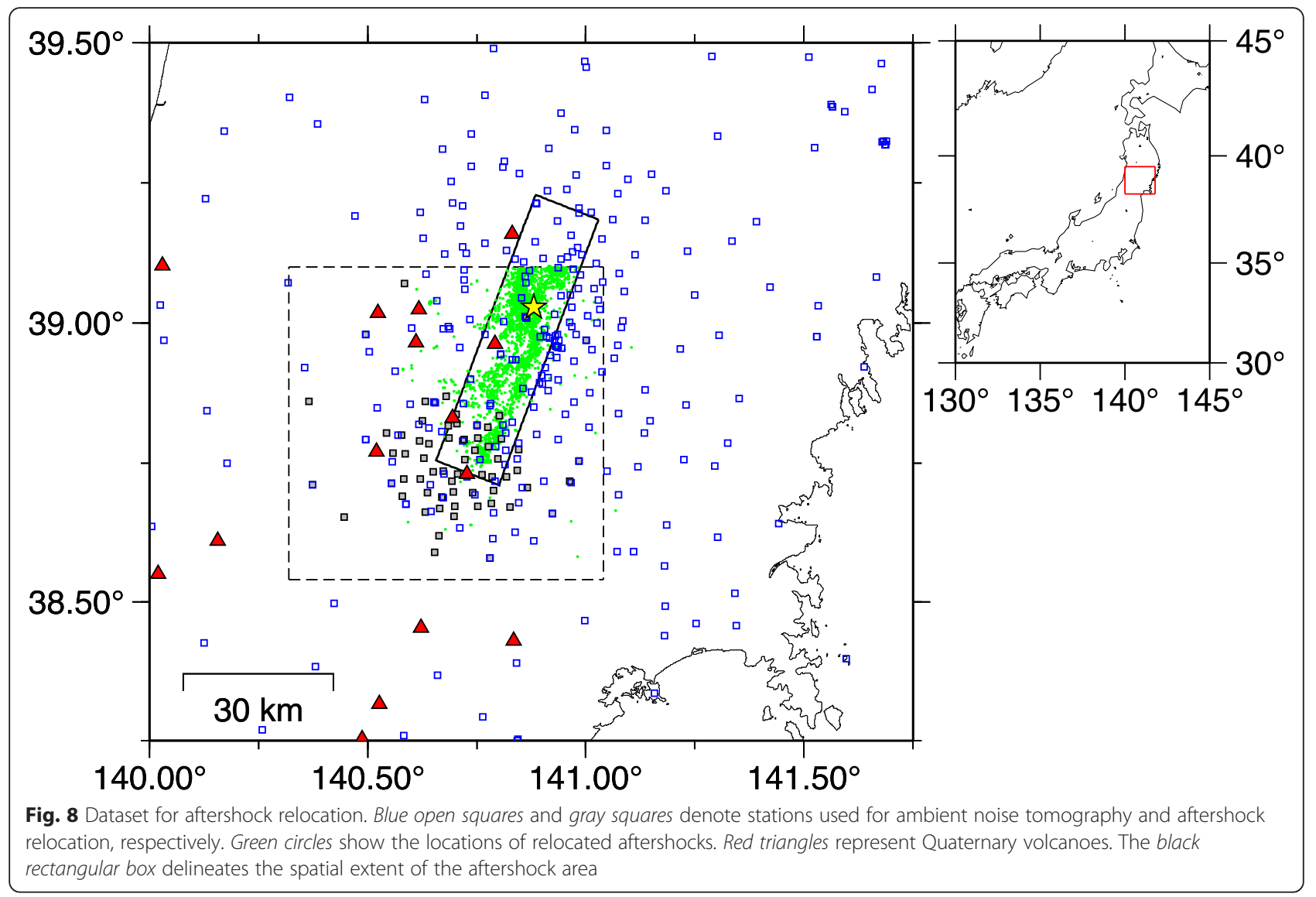

(a)
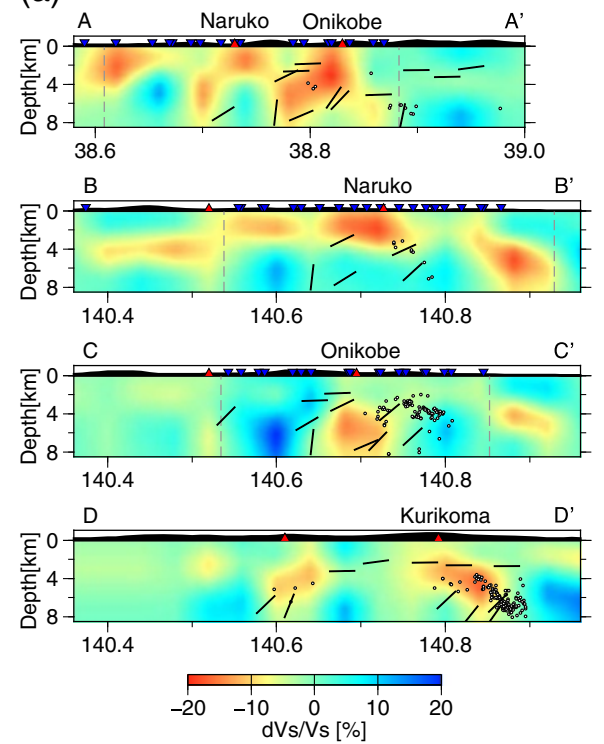

(b)
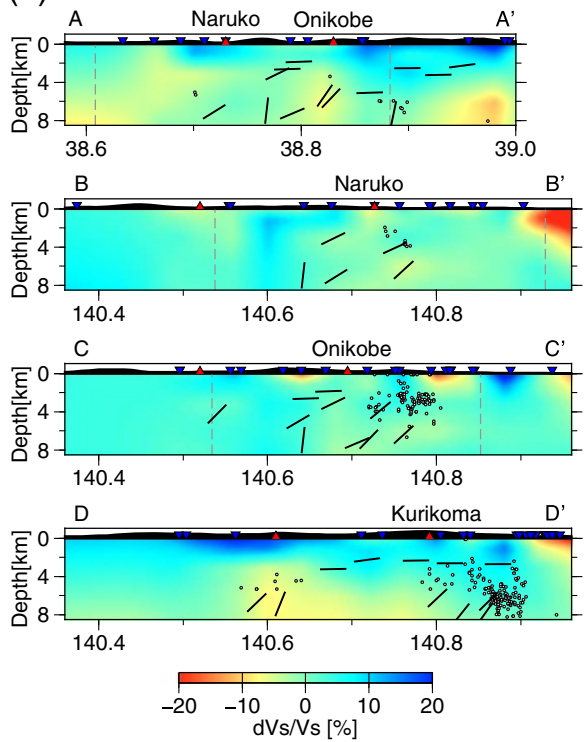

Fig. 9 Vertical cross sections of the $V_{s}$ models. The locations of lines A-A', B-B, C- $C^{\prime}$, and D-D' are shown in Fig. 7. a The $V_{s}$ model in this study. Red and blue triangles represent Quaternary volcanoes and stations, respectively. White circles denote aftershock locations with magnitudes greater than 1.5. Black lines show the locations of S-wave reflectors. Gray dashed lines indicate 0.3 of the diagonal elements of the resolution matrix at $0.4 \mathrm{~Hz}$. b The $V_{s}$ model of Okada et al. (2012) along the same lines as $\mathbf{a}$. The symbols are the same as $\mathbf{a}$ 
fluid is the plausible cause for the misoriented faulting, and therefore it is likely that the LVZ contains overpressurized fluid. These LVZs imply crustal softening and stress concentration in the Tohoku backbone range, and the presence of the geofluids characterizes different volcanic structures and complex faulting in the Naruko/ Onikobe volcanic area.

\section{Competing interests}

The authors declare that they have no competing interests.

\section{Authors' contributions}

All authors have made substantial contributions to the deployment of the seismic stations used in this study. All authors read and approved the final manuscript.

\section{Acknowledgements}

This study was supported by a grant from the Scientific Research Program on Innovative Areas, "Geofluids: Nature and Dynamics of Fluids in Subduction Zones" at the Tokyo Institute of Technology (21109002). We acknowledge JMA and NIED for providing the data. We are grateful to T. Matsuzawa, J. Nakajima, N. Uchida, M. Yamamoto, T. Sato, S. Hori, K. Tachibana, T. Kono, S. Hirahara, T. Nakayama, S. Suzuki, T. Demachi, T. Kaida, and Y. Chiba for the operation of the Naruko array.

\section{Received: 24 August 2015 Accepted: 22 December 2015}

\section{Published online: 16 January 2016}

\section{References}

Aki K (1957) Space and time spectra of stationary stochastic waves, with special reference to microtremors. Bull Earthquake Res Inst Univ Tokyo 35:415-456

Barmin MP, Ritzwoller MH, Levshin AL (2001) A fast and reliable method for surface wave tomography. Pure Appl Geophys 158:1351-1375. doi:10.1007/PL00001225

Bensen GD, Ritzwoller MH, Barmin MP, Levshin AL, Lin F-C, Moschetti MP, Shapiro NM, Yang Y (2007) Processing seismic ambient noise data to obtain reliable broad-band surface wave dispersion measurements. Geophys J Int 169:1239-1260. doi:10.1111/1.1365-246X.2007.03374.x

Brocher T (2005) Empirical relations between elastic wave speeds and density in the Earth's crust. Bull Seismol Soc Am 95:2081-2092. doi:10.1785/0120050077

Dziewonski A, Bloch S, Landisman M (1969) Technique for the analysis of transient seismic signals. Bull Seismol Soc Am 59(1):427-444

Ekström G, Abers GA, Webb SC (2009) Determination of surface-wave phase velocities across USArray from noise and Aki's spectral formulation. Geophys Res Lett 36, doi:10.1029/2009GL039131

Froment B, Campillo M, Roux P, Gouédard P, Verdel A, Weaver R (2010) Estimation of the effect of nonisotropically distributed energy on the apparent arrival time in correlations. Geophysics 75:85-93. doi:10.1190/1.3483102

Gardner GHF, Gardner LW, Gregory AR (1974) Formation velocity and density - the diagnostic basics for stratigraphic traps. Geophysics 39:770-780

Hasegawa A, Nakajima J, Uchida N, Okada T, Zhao D, Matsuzawa T, Umino N (2009) Plate subduction, and generation of earthquakes and magmas in Japan as inferred from seismic observations: An overview. Gondwana Research 16:370-400

Hasselman KA (1963) A statistical analysis of the generation of microseisms. Rev Geophys 1:177-210

Hori S, Umino N, Kono T, Hasegawa A (2004) Distinct S-wave reflectors (Bright Spots) extensively distributed in the crust and upper mantle beneath the Northeastern Japan Arc. J Seismol Soc Japan Second Ser 56:435-446

linuma T, Ohzono M, Ohta Y, Miura S, Kasahara M, Takahashi H, Sagiya T, Matsushima T, Nakao S, Ueki S, Tachibana K, Sato T, Tsushima H, Takatsuka K, Yamaguchi T, Ichiyanagi M, Takada M, Ozawa K, Fukuda M, Asahi Y, Nakamoto M, Yamashita Y, Umino N (2009) Aseismic slow slip on an inland active fault triggered by a nearby shallow event, the 2008 Iwate-Miyagi Nairiku earthquake (Mw6.8). Geophys Res Lett 36:L20308. doi:10.1029/2009GL040063

Jaxybulatov K, Shapiro N, Koulakov I, Mordret A, Landès M, Sens-Schönfelder C (2014) A large magmatic sill complex beneath the Toba caldera. Science 346(6209):617-619. doi:10.1126/science.1258582

Jay JA, Pritchard ME, West ME, Christensen D, Haney M, Minaya E, Sunaqua M, McNutt SR, Zabala M (2012) Shallow seismicity, triggered seismicity, and ambient noise tomography at the long-dormant Uturuncu Volcano. Bolivia Bull Volcanol 74:817-837. doi:10.1007/s00445-011-0568-7

Li H, Bernardi F, Michelini A (2009) Surface wave dispersion measurements from ambient seismic noise analysis in Italy. Geophys J Int 180:1242-1252. doi:10.1111/j.1365-246X.2009.04476.x

Lin F-C, Moschetti MP, Ritzwoller MH (2008) Surface wave tomography of the western United States from ambient seismic noise: Rayleigh and Love wave phase velocity maps. Geophys I Int 173:281-298. doi:10.1111/j.1365-246X.2008.03720.x

Longuest-Higgins MS (1950) A theory of the origin of microseisms. Philosophical Transactions of the Royal Society of London, Series A, Mathematical and Physical Sciences 243(857):1-35

Masterlark T, Haney M, Dickinson H, Fournier T, Searcy C (2010) Rheologic and structural controls on the deformation of Okmok volcano, Alaska: FEM, InSAR, and ambient noise tomography. J Geophys Res 115, B02409. doi:10.1029/2009JB006324

Matsumoto S, Hasegawa A (1996) Distinct S wave reflector in the midcrust beneath Nikko-Shirane volcano in the northeastern Japan arc. J Geophys Res 101:3067-3083

Miura S, Sato T, Hasegawa A, Suwa Y, Tachibana K, Yui S (2004) Strain concentration zone along the volcanic front derived by GPS observations in NE Japan arc. Earth Planets Space 56:1347-1355

Mordret A, Rivet D, Landès M, Shapiro NM (2015) Three-dimensional shear velocity anisotropic model of Piton de la Fournaise Volcano (La Réunion Island) from ambient seismic noise. J Geophys Res Solid Earth 120, doi:10.1002/2014JB011654

Moschetti MP, Ritzwoller MH, Shapiro NM (2007) Surface wave tomography of the western United States from ambient seismic noise: Rayleigh wave group velocity maps. Geochem Geophys Geosyst 8, doi:10.1029/2007GC001655

Nagaoka Y, Nishida K, Aoki Y, Takeo M, Ohminato T (2012) Seismic imaging of magma chamber beneath an active volcano. Earth Planet Sci Lett 333-334:1-8. doi:10.1016/j.epsl.2012.03.034

Nakajima J, Hasegawa A (2003) Tomographic imaging of seismic velocity structure in and around the Onikobe volcanic area, northeastern Japan: implications for fluid distribution. J Volcanol Geotherm Res 127:1-18. doi:10.1016/S0377-0273(03)00155-0

Nataf HC, Nakanishi I, Anderson DL (1986) Measurements of mantle wave velocities and inversion for lateral heterogeneities and anisotropy part III: inversion. J Geophys Res 91:7261-7307

Nicolson H, Curtis A, Baptie B, Galetti E (2012) Seismic interferometry and ambient noise tomography in the British Isles. Proc Geol Assoc 123(1):74-86

Ogawa Y, Ichiki M, Kanda W, Asamori K (2014) Three-dimensional magnetotelluric imaging of crustal fluids and seismicity around Naruko volcano, NE Japan. Earth Planets Space 66:158. doi:10.1186/s40623-014-0158-y

Ohta Y, Ohzono M, Miura S, linuma T, Tachibana K, Takatsuka K, Miyao K, Sato T, Umino N (2008) Coseismic fault model of the 2008 Iwate-Miyagi Nairiku earthquake deduced by a dense GPS network. Earth Planets Space 60:1197-1201

Okada T, Umino N, Hasegawa A (2010) Deep structure of the Ou mountain range strain concentration zone and the focal area of the 2008 IwateMiyagi Nairiku earthquake, NE Japan—seismogenesis related with magma and crustal fluid. Earth Planets Space 62:347-352. doi:10.5047/ eps.2009.11.005

Okada T, Umino N, Hasegawa A (2012) Group for the aftershock observations of the Iwate-Miyagi Nairiku Earthquake in 2008. Hypocenter distribution and heterogeneous seismic velocity structure in and around the focal area of the 2008 Iwate-Miyagi Nairiku Earthquake, NE Japan—-possible seismological evidence for a fluid driven compressional inversion earthquake. Earth Planets Space 64:717-728. doi:10.5047/eps.2012.03.005

Okada T, Matsuzawa T, Nakajima J, Uchida N, Yamamoto M, Hori S, Kono T, Nakayama T, Hirahara S, Hasegawa A (2014) Seismic velocity structure in and around the Naruko volcano, NE Japan, and its implications for volcanic and seismic activities. Earth Planets Sp 66:114. doi:10.1186/18805981-66-114

Saito M. (1988). DISPER80: a subroutine package for the calculation of seismic normal-mode solutions, in Seismological Algorithms: Computational Methods and Computer Programs, Academic Press, San Diego, 293-319.

Shapiro NM, Campillo M, Stehly L, Ritzwoller MH (2005) High-resolution surface-wave tomography from ambient seismic noise. Science 307:1615-1618. doi:10.1126/science.1108339

Shomali ZH, Shirzad T (2015) Crustal structure of Damavand volcano, Iran, from ambient noise and earthquake tomography. J Seismol 19:191-200

Sibson RH (1990) Rupture nucleation on unfavorably oriented faults. Bull Seismol Soc Am 80:1580-1604 
Sibson RH (2009) Rupturing in overpressured crust during compressional inversion - the case from NE Honshu, Japan. Tectonophysics 473:404-416. doi:10.1016/j.tecto.2009.03.016

Takada Y, Kobayashi T, Masato F, Murakami M (2009) Coseismic displacement due to the 2008 Iwate-Miyagi Nairiku earthquake detected by ALOS/PALSAR: preliminary results. Earth Planets Space 61:9-12

Takada Y, Fukushima Y (2013) Volcanic subsidence triggered by the 2011 Tohoku earthquake in Japan. Nature Geoscience 6:637-641. doi:10.1038/ngeo1857

Tarantola A, Valette B (1982) Generalized nonlinear inverse problems solved using the least squares criterion. Rev Geophys Space Phys 20:219-232

Ueno H, Hatakeyama S, Aketagawa T, Funasaki J, Hamada N (2002) Improvement of hypocenter determination procedures in the Japan Meteorological Agency (in Japanese with English abstract). Q J Seismol 65:123-134

Umino N, Ujikawa H, Hori S, Hasegawa A (2002) Distinct S-wave reflectors (bright spots) detected beneath the Nagamachi-Rifu fault, NE Japan. Earth Planet Sp 54:1021-1026

Weaver R, Froment B, Campillo M (2009) On the correlation of non-isotropically distributed ballistic scalar diffuse waves. J Acoust Soc Am 126:1817-1826

Yang Y, Ritzwoller MH, Jones CH (2011) Crustal structure determined from ambient noise tomography near the magmatic centers of the Coso region, southeastern California. Geochem Geophys Geosyst 12, Q02009. doi:10.1029/2010GC003362

Yoshida K, Hasegawa A, Okada T, Takahashi H, Kosuga M, Iwasaki T, Yamanaka Y, Katao H, lio Y, Kubo A, Matsushima T, Miyamachi H, Asano Y (2014) Pore pressure distribution in the focal region of the 2008 M7.2 Iwate-Miyagi Nairiku earthquake. Earth Planets Space 66:59. doi:10.1186/1880-5981-66-59

Yoshizawa K, Kennett BLN (2002) Determination of the influence zone for surface wave paths. Geophys J Int 149:440-453. doi:10.1046/j.1365-246X.2002.01659.x

Zhang H, Thurber C (2003) Double-difference tomography: the method and its application to the Hayward Fault, California. Bull Seismol Soc Am 93:1875-1889

\section{Submit your manuscript to a SpringerOpen ${ }^{\circ}$ journal and benefit from:}

- Convenient online submission

- Rigorous peer review

- Immediate publication on acceptance

- Open access: articles freely available online

- High visibility within the field

- Retaining the copyright to your article

Submit your next manuscript at $\boldsymbol{s p r i n g e r o p e n . c o m ~}$ 